\title{
Hombres y ejército en Galicia: la leva de 1762
}

\author{
Ofelia Rey Castelao *
}

La intención que perseguimos en estas páginas ' es demostrar que las modificaciones llevadas a cabo por los Borbones en el sistema de reclutamiento de hombres para el ejército, más, quizá, que el incremento en el volumen de los contingentes a aportar, estuvieron en la base de la fuerte resistencia de los gallegos a cualquier servicio militar, constatable a través de diversas fuentes impresionistas y deducible del grave problema que los prófugos constituyeron en todo momento ${ }^{2}$. Muy en especial, la forma de ejecución de la leva de 1762, extremadamente rigurosa, provocó una fuerte reacción, reflejada en protestas de las autoridades locales $y$, sobre todo, en el masivo recurso a todos los tipos posibles de excepción para eludir el servicio. Es precisamente esta leva la que centrará nuestro interés, pero procuraremos situarla en el contexto más amplio de las reformas militares del XVIII y su aplicación en Galicia.

Debe tenerse en cuenta que desde la reforma de 1703 por la que se establecía la leva por sorteo del $1 \%$, menudearon las quejas elevadas desde Galicia ${ }^{3}$, pero el trato dado a este Reino no parece haber sido diferente al otorgado a otros territorios de la monarquía e incluso en un principio se benefició de exenciones parciales como compensación a su contribución a la atención y vigilancia de las costas ${ }^{4}$; esto no evitó que en 1706 y 1709, bajo ese régimen de cierta preferencia, los Capitanes

* Universidad de Santiago de Compostela.

Los resultados que aquí se presentan se han obtenido en el marco del proyecto de investigación financiado por la Xunta de Galicia, n. 21002A90.

2 De esta cuestión nos hemos ocupado brevemente en Eiras Roel, A., y Rey Castelao, O., Los gallegos y América. Madrid 1992, págs. 222 y ss. y por extenso en nuestra ponencia "Migraciones internas y medium-distance en Galicia, siglos XVI-XIX", Actas de la I Conferencia Europea de la Comisión Internacional de Demografía Histórica. Santiago 1993, vol. II, págs. 27 y ss.

3 Noticias de diversa procedencia y cariz pero siempre indicativas de un malestar fueron recogidas hace tres décadas por MEIJIOE PARDO, A., en "La emigración gallega intrapeninsular en el siglo XVIIIm, Estudios de Historia Social de España. Madrid 1960, pág. 463.

${ }_{4}^{4}$ Borreguero Beltran, C., El reclutamiento militar por quintas en la España del siglo xvill. Orígenes del servicio militar obligatorio. Valladolid 1989, pág. 87. 
Generales, Duque de Híjar y Marqués de Risbourough, tuviesen que denunciar ante José Grimaldo las dificultades encontradas para la ejecución de las levas ${ }^{5}$. A decir verdad, desde el punto de vista cuantitativo, Galicia sólo se vio comparativamente gravada en 1719, cuando se le exigió aportar el $27,1 \%$ de los hombres sorteados, pero entre las de 1726 y 1741 le correspondió del $9,8 \%$ de la primera al $12 \%$ de la última, cuando su verdadero peso demográfico era de un $13 \%$ aproximadamente; en 1762 , no obstante, vuelve a producirse un cierto incremento al imponerse a Galicia un cupo de 1.154 hombres que equivalían al $14,8 \%$ del total ${ }^{6}$. Habida cuenta de esto, consideramos que la resistencia obedeció a los cambios de forma, a una ejecución más cuidadosa de la recluta y a la incidencia de otros factores coincidentes después de la Guerra de Sucesión.

En primer lugar, tuvo un efecto no medible el cambio de control militar. Desde su instauración, los Gobernadores Capitanes Generales se habian encargado de esa función de modo casi exclusivo, pero habian tenido una fuerte limitación en los lugares de señorío, en donde las justicias se encargaban de las reclutas; para paliar este problema, el Capitán General Duque de Hijar traspasó en 1705 la responsabilidad completa a las justicias ordinarias y por lo tanto acababa, en teoría, con las desviaciones que provocaba la situación anterior ${ }^{7}$. Pero poco tiempo después, en 1712 , se instituia la Intendencia de Galicia y si bien su verdadero establecimiento habrá de esperar a 1718, ya en su primera etapa de funcionamiento recibió parte de las funciones militares hasta entonces exclusivas de los Capitanes Generales; se producía así una situación de dualidad y tirantez perfectamente visible cuando en 1712 el Intendente trató de realizar la leva de 4.000 hombres que le había sido encomendada y, tras la consiguiente oleada de descontento, el Capitán General consiguió la suspensión de su ejecución; en parte como consecuencia de este hecho, en 1716, el Gobernador recuperaba todas sus capacidades en materia militar. Es fácil de deducir que este antagonismo se reflejó en un «impasse" en las reclutas. Después de la suspensión y posterior restauración de la Intendencia (1718) la cuestión militar será siempre fuente de problemas entre ésta y los Capitanes Generales por la persistencia de la doble responsabilidad, aunque dependiendo de múltiples factores unas veces, en efec-

\footnotetext{
5 Fernández Vega, L., La Real Audiencia de Galicia, órgano de gobierno en el Antiguo Régimen (1480-1808). La Coruña 1982, págs. 297 y 298 del vol. Ill.

6 Nos valemos para esos cálculos de los datos que figuran en la obra de Borreguero, C., citada ya, págs. 155 y ss.

7 Fernández Vega, L., op. cit., vol. I, pág. 219.
} 
to, se estorbaron mutuamente y otras colaboraron y se complementaron como se esperaba de ambas instituciones ${ }^{8}$.

En segundo lugar, no puede desdeñarse el efecto concomitante de una fiscalidad al alza y con destino militar, las reclutas de peones y trabajadores cualificados para los arsenales de La Graña/El Ferrol, las requisas de carros y abastecimientos para éstos y en general para el ejército y la armada y, lo que es, sin duda, más relevante, la instauración de la Matrícula de Mar. Las siempre dificultosas levas de marinería se institucionalizaron de modo mucho más estable desde la implantación de la Matrícula en 1717 y sobre todo desde 1737, basada en el registro obligatorio de todos los marineros y pescadores y su división en clases susceptibles de ser movilizadas ${ }^{9}$. Con una orla marítima tan extensa, Galicia quedaba sometida así a un sistema de recluta estable comparativamente gravoso por cuanto a esto se unía el hecho de tener a la vez una larga frontera con Portugal.

En tercer lugar, la cuestión más concreta y específica de los cambios de forma de la recluta. La reforma de 1703 fijaba como norma general el sorteo, pero lo cierto es que había resultado impracticable en Galicia porque los mozos "viven desparramados por feligresias, habitaciones y moradas sueltas separadas por campos de cultivo o incultos, colinas, prados,... ${ }^{10}$, es decir, la dispersión de la población había díficultado aquella práctica hasta que en la leva de 1730 se obliga a su realización. Es precisamente ante esta leva, en la que se exigen sólo 525 hombres, y ante la de 1733 , en la que se piden 878 , cuando se produce la reacción más negativa; en 1726 Galicia había aprontado 787, pero parece haber sido el efecto combinado del cambio de sistema y de la proximidad de los dos requerimientos, lo que provocó la oposición y protesta general frente a su ejecución ${ }^{11}$.

Finalmente, existe una cuestión de fondo, la imposibilidad de aportar hombres para las levas a causa de la emigración, aunque no puede eludirse la doble lectura que este hecho sugiere, es decir, que las ausencias estuviesen motivadas en buena medida por las exigencias militares de la Corona. La interferencia de ambas cuestiones fue permanente a lo largo

- Granados loureda, J. A., Un ejemplo de comisariado en el Antiguo Régimen español: la Intendencia de Galicia, 1712-1775, Tesis de Licenciatura inédita. Santiago 1986, págs. 141 y ss.

9 Merino Navarro, J. P., La Armada española en el siglo xVIII. Madrid 1981, págs. 75 y ss.

10 Citado por Boraeguero, C., op. cit., pág. 317.

$"$ Meijide Pardo, A., op. cit., pág. 499 y ss. y Borreguero, C., op. cit. recogen noticias diversas que corroboran esta impresión. 
del XVIII y será especialmente intensa a partir de la implantación del servicio militar obligatorio de 1837. Habría que añadir un tercer elemento, la proximidad geográfica de Portugal, que convertía al país vecino en un objetivo idóneo para prófugos y desertores, posibilidad que había estado cerrada desde 1640 hasta 1714 por motivos bélicos; la apertura después de esta última fecha realmente no se vio entorpecida por las posteriores situaciones de guerra entre España y Portugal, como luego veremos.

La primera parte de la ecuación, es decir, la relación milicia/emigración oscila en su planteamiento a lo largo del XVIII. Así en 1712/13, la imposibilidad de hacer la leva se justificó porque «la mayor parte de los mozos solteros está en los Reinos de Castilla», lo que motivaba una notoria falta de gente ${ }^{12}$ y ante la de 1733 el concejo de Santiago exigía mayor vigilancia de las rutas del éxodo y que se prendiese «en las veredas de Castilla y Portugal a todos los mozos que pasasen a dichos reinos" ${ }^{13}$ para poder cubrir los cupos de hombres exigidos, pero en ese mismo año se eximia de servicio a los braceros gallegos que pasaban a la cava y siega en Castilla, en donde su contratación como mano de obra temporera era importante; esa orden se reitera en 1762 y años sucesivos, en pleno contexto de reestructuración general de las levas. En fechas posteriores, las denuncias de la imposibilidad de cubrir los cupos a causa del déficit de hombres se hacen más frecuentes y se imputan a la huida masiva a Portugal de los comprendidos en quintas ${ }^{14}$ : en 1764 el Capitán General hubo de dar orden de cerrar la frontera con aquel país, en 1775 el embajador de España en Lisboa informaba del elevado número de desertores llegados desde Galicia, y aunque en 1778 se firmaba el tratado bilateral para el intercambio de prófugos, este acuerdo parece haber tenido escasa repercusión real, de modo que las guerras finiseculares no hicieron más que agravar el problema.

No insistiremos en traer a colación las numerosas noticias que avalan ese aspecto, toda vez que no parece que haya duda sobre que el factor militar fue uno de los que surtió un efecto más directo sobre la emigración de varones jóvenes induciéndolos a irse para no tener que cumplir con un servicio duro y prolongado, pero de ninguna manera se puede considerar el único y, en última instancia, los movimientos migratorios remiten siempre a una casualidad socioeconómica. Sí insistiremos en cambio en

Citado por GaAnados, J. A., op. cit, pág. 141.

13 Citado por MEIJIDE, A., op. cit, págs. 499 y ss.

14 GonzÁlez LoPO, D., "La emigración a Portugal desde el S.O. de Galicia en los siglos XVIII al x|x", Coloquio internacional sobre emigraçâo-inmigraçâo portuguesa nos séculos xix-xx. Lisboa 1992. 
que este planteamiento derivó gran medida de los cambios formales llevados a cabo en el sistema de recluta: en el caso gallego todo indica que se puede considerar la normativa de 1762 para la realización de la leva de ese año como un hito claro en la reacción contra el servicio militar. La leva del 62 comportaba un incremento notable en los cupos habitualmente repartidos - a Galicia le tocaron 1.154 hombres- pero además se hacia para afrontar la guerra con Inglaterra y Portugal declarada a comienzos de ese año y se planteaba con un rigor inusitado en su ejecución ${ }^{15}$; por otra parte, si de un lado mantenía la antigua exención de servicio para los braceros que iban a Castilla, protegidos de los abusos a los que alli eran sometidos, de otro, la normativa por la que se regía recortaba otras exenciones como las referidas al clero. Fue precisamente el rigor de la ejecución lo que motivó una reacción generalizada reflejada en un recurso masivo a todas las posibles causas de exención.

Con ocasión de la R.O. de 24-3-1762 se procedió a reactualizar los vecindarios que servian de base a las levas, de modo que el Intendente envió mandato a los concejos y a los párrocos para hacer alistamiento a los varones solteros de 16 a 18 años y de 18 a 40 a partir de las actas de bautismo, comprobación esta última que trataba de velar por la exactitud del cómputo ${ }^{16}$. Obedeciendo a esa orden, en el verano, estación marcada por las ausencias laborales, se hizo el recuento contemplando los diversos motivos de excepción, de todo lo cual resultó una valiosa información estadística que pasamos a analizar.

El censo de mozos de $1762^{17}$ se realizó para toda Galicia, jurisdicción por jurisdicción, incluyendo en lista a 64.421 varones de 16 a 40 años.

15 En los fondos documentales de la Intendencia de Galicia se pueden encontrar informes como el que en 3-XI-1762 remite D. Francisco X. Chuecos, Alcalde Mayor de La Coruña, encargado por el Intendente para el cumplimiento de la quinta, en el que notifica el apremio a que había sometido a dos vecinos de S.S. de Bergondo, hasta que cen tanto que diesen quenta y presentasen al dicho Señor Intendente el primero a Benito Lorenzo y el seguno a Silvestre Don, sus hijos, a quien tocó la suerte para soldados... y aunque en fuerza de ello se les ha puesto y se allan en la cárcel pública... no los an presentado...", por todo lo cual se procedió al embargo de sus bienes (Archivo del Reino de Galicia, Intendente, leg. 37/143).

${ }_{16}$ Estamos mal informados del modo en que éste se realizó, pero no faltan las noticias sobre abusos en los que las justicias locales se valieron del temor de los mozos para obtener de ellos algunas sumas de dinero; en eso precisamente consiste la denuncia que en 2-2-1763 envía un cura de Brollón al Intendente en la que da cuenta de las dudosas operaciones de D. Juan Varela en las que había llegado a convocar a más de 200 hombres para la leva "y a unos les pedía 20 reales y a otros 30 reales, sin reparar que fuesen tuertos o mancos" al tiampo que había establecido "un tributo injusto que repartió (a los vecinos) representándoles que avia tenido escesivos gastos en conducir tres milicianos a Chaves y otros a la ciudad de Lugo y de esposas para asegurarlos y en los guardas de conducción..." (Archivo del Reino de Galicia, Intendente, leg. 37/150, s. f.

1 Archivo General de Simancas, Secretaria de Guerra, lib. 5684. 
No es posible comparar esta cifra global con ningún otro dato censal hasta el censo de Floriblanca de 1787:

\begin{tabular}{lrrrrrr}
\hline \multicolumn{1}{c}{ Provincia } & \multicolumn{2}{c}{1762} & \multicolumn{2}{c}{1787} & \multicolumn{2}{c}{ Diferencia } \\
\hline & Núm & $\%$ & Núm & \multicolumn{1}{c}{$\%$} & Núm & $\%$ \\
Betanzos & 5.222 & 8,1 & 14.371 & 13,2 & 9.149 & 63,7 \\
Coruña & 1.632 & 2,5 & 3.342 & 3,1 & 1.710 & 51,1 \\
Lugo & 10.671 & 16,6 & 21.117 & 19,4 & 10.446 & 49,5 \\
Mondodeño & 3.592 & 5,6 & 7.124 & 6,6 & 3.532 & 49,6 \\
Orense & 18.539 & 28,8 & 27.325 & 25,1 & 8.786 & 32,1 \\
Santiago & 17.843 & 27,7 & 25.911 & 23,8 & 8.068 & 31,1 \\
Tuy & 6.922 & 10,7 & 9.491 & 8,7 & 2.569 & 27,0 \\
\hline TOTAL & 64.421 & 100,0 & 108.681 & 100,0 & 44.260 & 40,7 \\
\hline
\end{tabular}

La diferencia entre una fuente y otra a todas luces no es imputable a un crecimiento demográfico entre 1762 y 1787 por inexistente, de lo que se deduce que en 1762 hubo una ocultación importante de efectivos, aunque en esa diferencia habría que computar a determinados exentos - frailes, ordenados, estudiantes, jóvenes con hermanos en el ejército, matriculados de $\operatorname{mar}^{18}$, etc.-, que no se incluyeron en las otras excepciones contempladas en el censo y, por supuesto, a los mozos de algunas localidades en las que el control no llegó a hacerse, y muy probablemente a los emigrados con carácter definitivo. La distribución porcentual de las cifras nos permite obrar con relativa seguridad partiendo de la premisa de que la ocultación que haya habido presumiblemente haya sido homogénea.

El censo de mozos establece dos cálculos diferenciados para los tramos de edad de 16/18 años y de 18 a 40 y, en cada caso, las distintas situaciones de exención:

${ }_{18}$ Es imposible evaluar esas otras situaciones, pero téngase en cuenta que en 1787 había censados en Galicia 4.429 estudiantes y más de 13.000 eclesiásticos, una parte de los cuales estaria entre los 18 y los 40 años (Véase EIRAS ROEL, A., "Sobre la distribución profesional de la población en la España de Carlos III. Examen crítico de las cifras censales", Coloquio Internacional: Carlos III y su siglo. Madrid 1990, vol, II, págs. 505 y ss. 
Hombres y ejército en Galicia: La Leva de 1762

GRUPO DE 16 A 18 AÑOS

\begin{tabular}{lrrrrrrrr}
\hline & \multicolumn{1}{c}{ Nobles } & Aforados & $\begin{array}{c}\text { Hijos } \\
\text { únicos }\end{array}$ & $\begin{array}{c}\text { Cabezas } \\
\text { casa }\end{array}$ & $\begin{array}{c}\text { Sin } \\
\text { excep. }\end{array}$ & $\begin{array}{c}\text { Ausen- } \\
\text { tes }\end{array}$ & Inútiles & TOTAL \\
\hline Coruña & 4 & - & 19 & 2 & 242 & 4 & 10 & 281 \\
$\%$ & 1,4 & 0,0 & 6,8 & 0,7 & 86,1 & 1,4 & 3,6 & 100,0 \\
Betanzos & 8 & 2 & 70 & 8 & 677 & 44 & 73 & 882 \\
$\%$ & 0,9 & 0,2 & 7,9 & 0,9 & 76,8 & 5,0 & 8,3 & 100,0 \\
Lugo & 134 & - & 80 & 11 & 830 & 41 & 187 & 1.283 \\
$\%$ & 10,4 & 0,0 & 6,2 & 0,9 & 64,7 & 3,2 & 14,6 & 100,0 \\
Santiago & 26 & 3 & 431 & 47 & 2.365 & 432 & 224 & 3.528 \\
$\%$ & 0,7 & 0,1 & 12,2 & 1,3 & 67,0 & 12,2 & 6,3 & 100,0 \\
Tuy & 7 & - & 194 & 48 & 861 & 208 & 76 & 1.394 \\
$\%$ & 0,5 & 0,0 & 13,9 & 3,4 & 61,8 & 14,9 & 5,5 & 100,0 \\
Mondoñedo & 10 & - & 41 & 2 & 427 & 13 & 41 & 534 \\
$\%$ & 1,9 & 0,0 & 7,7 & 0,4 & 80,0 & 2,4 & 7,7 & 100,0 \\
Orense & 116 & 3.156 & - & - & 160 & - & - & 3.432 \\
$\%$ & 3,4 & 92,0 & 0,0 & 0,0 & 4,6 & 0,0 & 0,0 & 100,0 \\
\hline
\end{tabular}

A la luz de estos datos se observa una situación anómala en la provincia de Orense en la que, sin duda con la connivencia de las autoridades encargadas de elaborar las listas, se clasificó como aforados al $92 \%$ de los varones de 16/18 años, según lo cual todos ellos serian receptores de rentas o estarían encargados de otras responsabilidades en ese mismo orden de cosas, de modo que el cupo de útiles resulta extraordinariamente bajo con respecto a las otras provincias. En el cómputo total de este grupo de edad es, sin embargo, lo bastante joven como para no poder beneficiarse de ciertas exenciones: no han accedido, quienes pudieran hacerlo, a dedicaciones o situaciones "de fuero" -Cruzada, Inquisición y percepción de rentas-, su incorporación a las migraciones estacionales es minoritaria, la proporción de inválidos o inútiles es asimismo baja debido a su incorporación relativamente reciente a trabajos de fuerza, y la edad de los padres hace que sólo un sector restringido sean hijos de sexagenarios o de viudas $y$, por lo tanto, responsables de la economía familiar. Por todo esto, el número de no exceptuados, prescindiendo del caso orensano, es en todas las provincias muy elevado, entre el 60 y el $86 \%$, mientras que en el grupo de 18 a 40 años oscila entre el 30,3 y el $53,5 \%$. La observación de este otro tramo es sin duda más reveladora, por cuanto el transcurso del tiempo necesariamente reacomoda a los jóvenes en una nueva distribución: 
GRUPO DE 18 A 40 AÑOS

\begin{tabular}{|c|c|c|c|c|c|c|c|c|}
\hline & Nobles & Aforados & $\begin{array}{c}\text { Hijos } \\
\text { únicos }\end{array}$ & $\begin{array}{c}\text { Cabezas } \\
\text { casa }\end{array}$ & $\begin{array}{c}\operatorname{Sin} \\
\text { excep. }\end{array}$ & $\begin{array}{c}\text { Ausen- } \\
\text { tes }\end{array}$ & Inútiles & TOTAL \\
\hline Coruña & 57 & 17 & 311 & 27 & 726 & 138 & 82 & 1.358 \\
\hline$\%$ & 4,2 & 1,3 & 22,9 & 2,0 & 53,5 & 10,1 & 6,0 & 100,0 \\
\hline Betanzos & 104 & 29 & 1.056 & 239 & 2.105 & 375 & 432 & 4.340 \\
\hline$\%$ & 2,4 & 0,7 & 24,3 & 5,5 & 48,5 & 8,6 & 10,0 & 100,0 \\
\hline Lugo & 1.227 & 13 & 1.157 & 347 & 4.428 & 1.166 & 1.050 & 9.388 \\
\hline$\%$ & 13,1 & 1,4 & 12,3 & 3,7 & 47,1 & 12,4 & 11,2 & 100,0 \\
\hline Santiago & 260 & 94 & 3.150 & 757 & 4.511 & 3.988 & 1.555 & 14.315 \\
\hline$\%$ & 1,8 & 0,7 & 22,0 & 5,3 & 31,5 & 27,9 & 10,9 & 100,0 \\
\hline \multirow[t]{2}{*}{ Tuy } & 89 & 19 & 1.588 & 524 & 1.674 & 1.158 & 476 & 5.528 \\
\hline & 1,8 & 0,3 & 28,7 & 9,5 & 30,3 & 20,9 & 8,6 & 100,0 \\
\hline Mondoñedo & 218 & 5 & 865 & 232 & 1.141 & 278 & 319 & 3.058 \\
\hline$\%$ & 7,1 & 0,2 & 28,3 & 7,6 & 37,3 & 9,1 & 10,4 & 100,0 \\
\hline Orense & 1.132 & 10.834 & - & - & 3.141 & - & - & 15.107 \\
\hline$\%$ & 7,5 & 71,7 & - & - & 20,8 & - & - & 100,0 \\
\hline
\end{tabular}

Las cifras de Orense confirman una actitud consentidora por parte de los concejos y párrocos, de modo que aquellos que no disponían de la condición de hidalgos o nobles fueron en su mayor parte inscritos como aforados, todos ellos como perceptores de rentas. Evidentemente, los orensanos se limitaron a extremar una manifestación bien perceptible, esto es, la tendencia a huir del servicio por la vía legal utilizando todas las posibilidades de exención. Éstas, sin embargo, vienen dadas por realidades sociales y económicas de base que los datos de la leva traducen y en los que nos detendremos por cuanto el censo de mozos de 1762 pasa así a convertirse en una fuente macro-estadística de gran importancia. Procedemos, por lo tanto, a estudiar cada una de las grandes causas de excepción como fórmula para analizar los componentes sociales y económicos que se traslucen a través del censo.

\section{A. LA EXENCIÓN POR PRIVILEGIOS}

De las dos variantes posibles, por nobleza o "por fuero", el cartografiado de su distribución - véase mapa 1- no deja lugar a dudas: el mayor número de nobles, en realidad, simples hidalgos en su mayoría de condición humilde, se corresponde con la Galicia interior - provincias de Lugo y Orense y parte oriental de Mondoñedo-, descendiendo progresivamente de Este o Oeste, de modo que el río Sil establece una especie de frontera entre la zona de hidalguía abundante y la de hidalguía escasa. En la Galicia occidental sólo hay concentraciones superiores al $10 \%$ en 


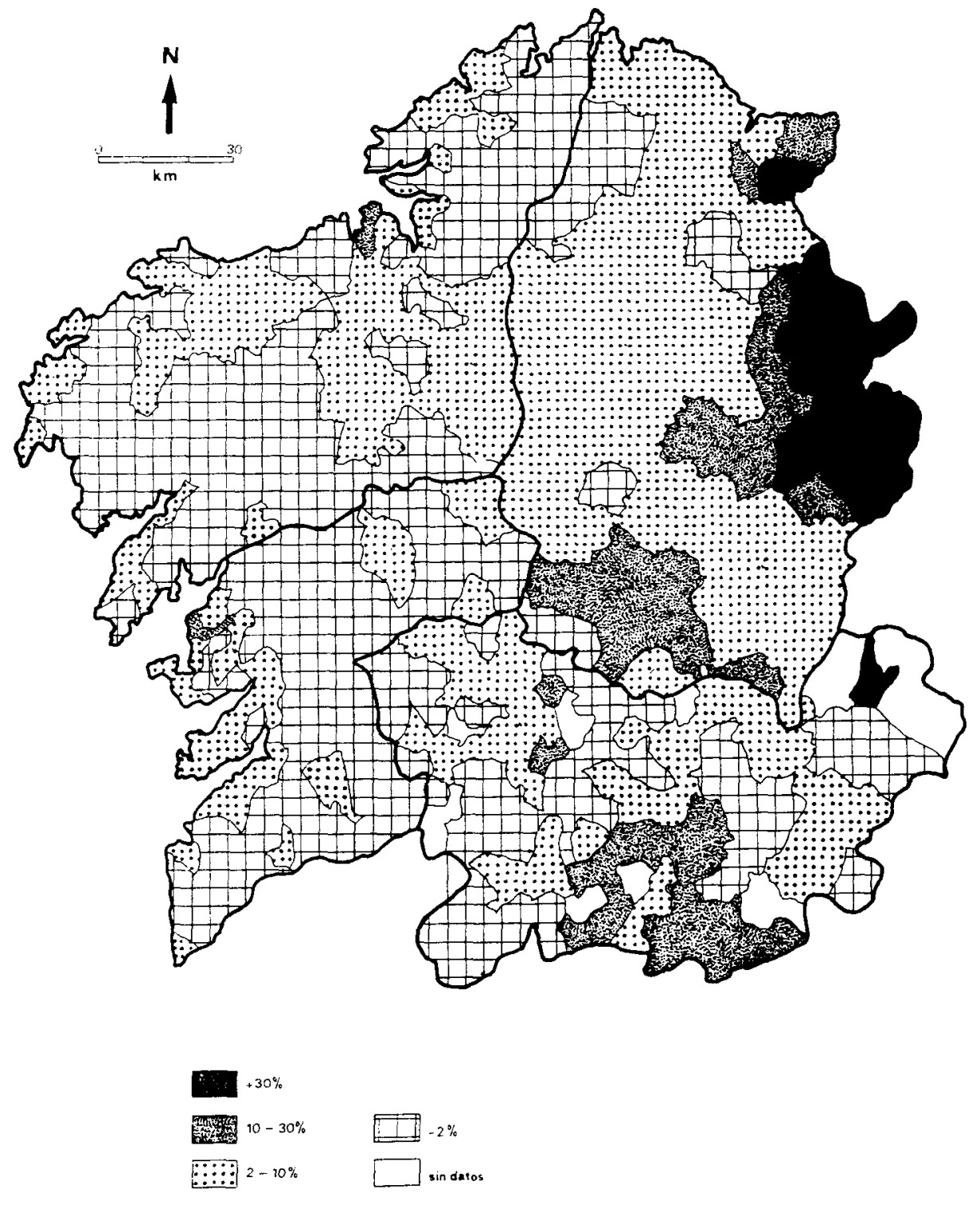

Mapa 1. Exención por nobleza. 
municipios en los que se ubican villas o ciudades, pero lo habitual es que se sitúen en la banda inferior al $2 \%$, mientras en el extremo opuesto -municipios lucenses de Trabada, Fonsagrada, Negueira de Muñiz, Navia de Suarna, Becerreá y Cervantes-, se supera el $30 \%$ de los alistados, mostrándose como una franja que prolonga en Galicia la numerosa población asturiana de condición hidalga. Como es lógico, la fuente empleada tiende a incrementar la representación nobiliar al tener en cuenta sólo población masculina, pero encaja con otras cifras ofrecidas por las monografías rurales ${ }^{19}$ y sugiere la idea de una hidalguía mayoritariamente modesta en la Galicia oriental y más rica y potente en la occidental, allí donde era menos numerosa.

La segunda exención de este tipo es la referida a quienes gozaban de fuero de Cruzada o Inquisición o eran perceptores de rentas reales. Es esta variante en la que se produjo la anomalía más distorsionadora, que prácticamente deja fuera de análisis a la provincia de Orense. No obstante, la observación cartográfica - mapa 2-, permite ver que no se utilizó de modo sistemático este subterfugio, lo que se explica por la posibilidad de emplear el fuero nobiliar; la suma de los dos tipos de privilegio sitúa a Orense como la provincia con menor porcentaje de individuos útiles para el servicio. En el resto de Galicia rara vez la excepción que comentamos superó el $1 \%$ del total, coincidiendo las máximas concentraciones allí donde hay núcleos urbanos; en conjunto, sólo 177 varones de $18 / 40$ años y 5 de 16/18 acreditan esta situación, de los que sólo uno pertenecía a la Inquisición, 11 al fuero de Cruzada y el resto eran perceptores de rentas; debe tenerse en cuenta que en 1787 sólo figuran como dependientes de Cruzada 225 individuos, 101 de la Inquisición y 1.787 empleados del Rey, de modo que sólo una minoría muy restringida podría eximirse de servicio por esta vía.

\section{B. LA EXENCIÓN POR CAUSAS FAMILIARES}

Como es sabido, los varones casados y viudos no entraron en lista en las levas del XVIII, pero se preveían otras situaciones familiares que entrañaban exención, quedando libres de quintas los hijos únicos de madre viuda o de padre sexagenario, quienes tuviesen hermanos en el ejército y los solteros con casa propia. El censo de mozos de 1762 contempla la primera y la última de esas exenciones en todas las provincias salvo en

19 En Fonsagrada y Negueira de Muñiz, por ejemplo, en 1787 los hidalgos superaban el $14,9 \%$ y en la provincia de Mondoñedo a mediados del xVIII se situaba en el $3 \%$ SAAVEDRA, P., Economia rural en la Montaña lucense. Santiago 1979, pág. 23. 


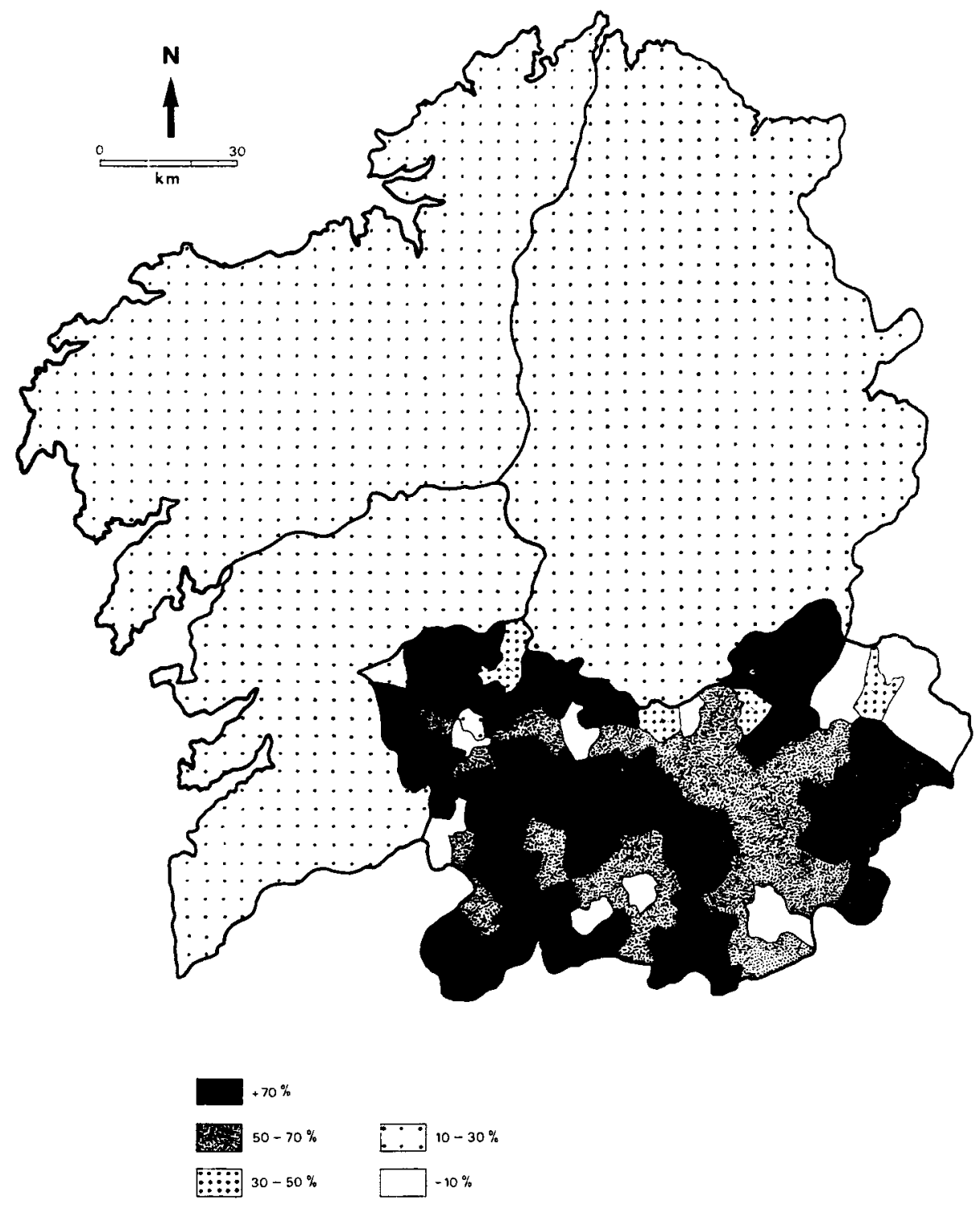

Mapa 2. Exención por "gozar fuero». 
Orense. De los datos de las otras provincias se deduce que en el tramo de 18 a 40 años - prescindimos del otro por lo ya dicho-, las exenciones por causa familiar favorecieron al $27 \%$ de los alistados, comprendiendo un $21,4 \%$ a los hijos únicos y sólo el $5,6 \%$ a los cabezas de casa. Sin embargo, la distribución zonal es muy dispar, de modo que Tuy, con el $38,2 \%$, Mondoñedo con el $35,9 \%$ y Santiago con el $27,3 \%$ superan con mucho las cifras del resto de Galicia.

La lectura de los mapas correspondientes - números 3,4 y 5 -, nos remite claramente a la distribución de los modelos de comportamiento familiar de la Galicia del siglo XVIII establecidos por I. DUBERT ${ }^{20}$, de modo que podemos decir que las exenciones familiares coinciden con la mitad occidental gallega, en especial en la franja costera y en la banda litoral de la Galicia cantábrica, en donde predominaba la familia nuclear de pequeño tamaño y un sistema de transmisión del patrimonio familiar relativamente igualitario, con un gran número de hogares regentados por viudas y solteras $y$, en medida menor, por viudos y solteros. Las exenciones familiares son mucho menos frecuentes, sólo el $16 \%$, en la Galicia interior, en todo lo que constituye la antigua provincia de Lugo, en donde la familia troncal y de tamaño amplio tienen su predominio junto con un sistema de mejora larga a favor de un solo hijo, siendo minoritarios los hogares regentados por mujeres o por solteros y viudos. El cartografiado refleja de modo fiel, por lo tanto, la estructura de la familia gallega y sus variantes zonales. Comprobaremos el funcionamiento de esto a través de la comparación de las proporciones ofrecidas por el censo de mozos y el tamaño del grupo doméstico a partir de los datos del censo de 1787 elaborados por A. EIRAS ${ }^{21}$; como puede observarse en la siguiente tabla, el tamaño del grupo familiar es considerablemente mayor en Lugo, lo que concuerda con la baja proporción de exentos por causa familiar y, en general, la concordancia corrobora nuestras afirmaciones, aun siendo conscientes de que las distintas causas de excepción se solapan entre sí:

\section{Exenciones familiares Tamaño familia (1787)}

\begin{tabular}{llcc}
\hline Coruña & $24,9 \%$ & 4,03 & indv./hogar \\
Betanzos & $29,8 \%$ & 4,22 & $"$, \\
Lugo & $16,0 \%$ & 4,72 & $"$ \\
Santiago & $27,3 \%$ & 4,00 & $"$ \\
Tuy & $38,2 \%$ & 3,99 & $"$ \\
Mondoñedo & $35,9 \%$ & 4,48 & \\
\hline
\end{tabular}

20 Dubert García, I., Historia de la familia en Galicia durante la época moderna, 1550-1830. La Coruña, 1992.

21 EIRAS RoEL, A., “Galicia, estructura y caracteres de la población gallega en el censo de Floridablanca", en La población española en 1787. Murcia 1992, pág. 399. 


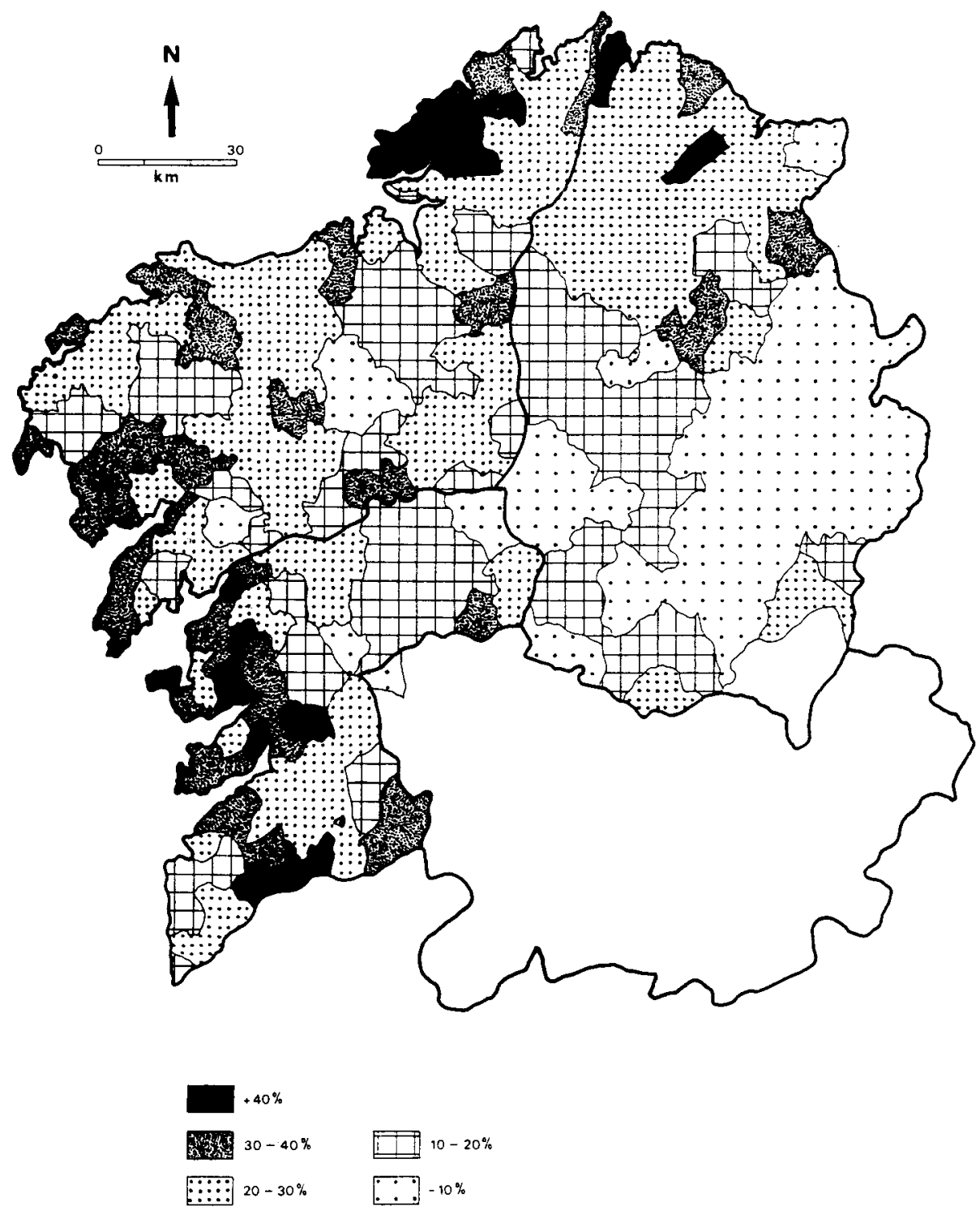

Mapa 3. Exceptuados por «hijos únicos». 


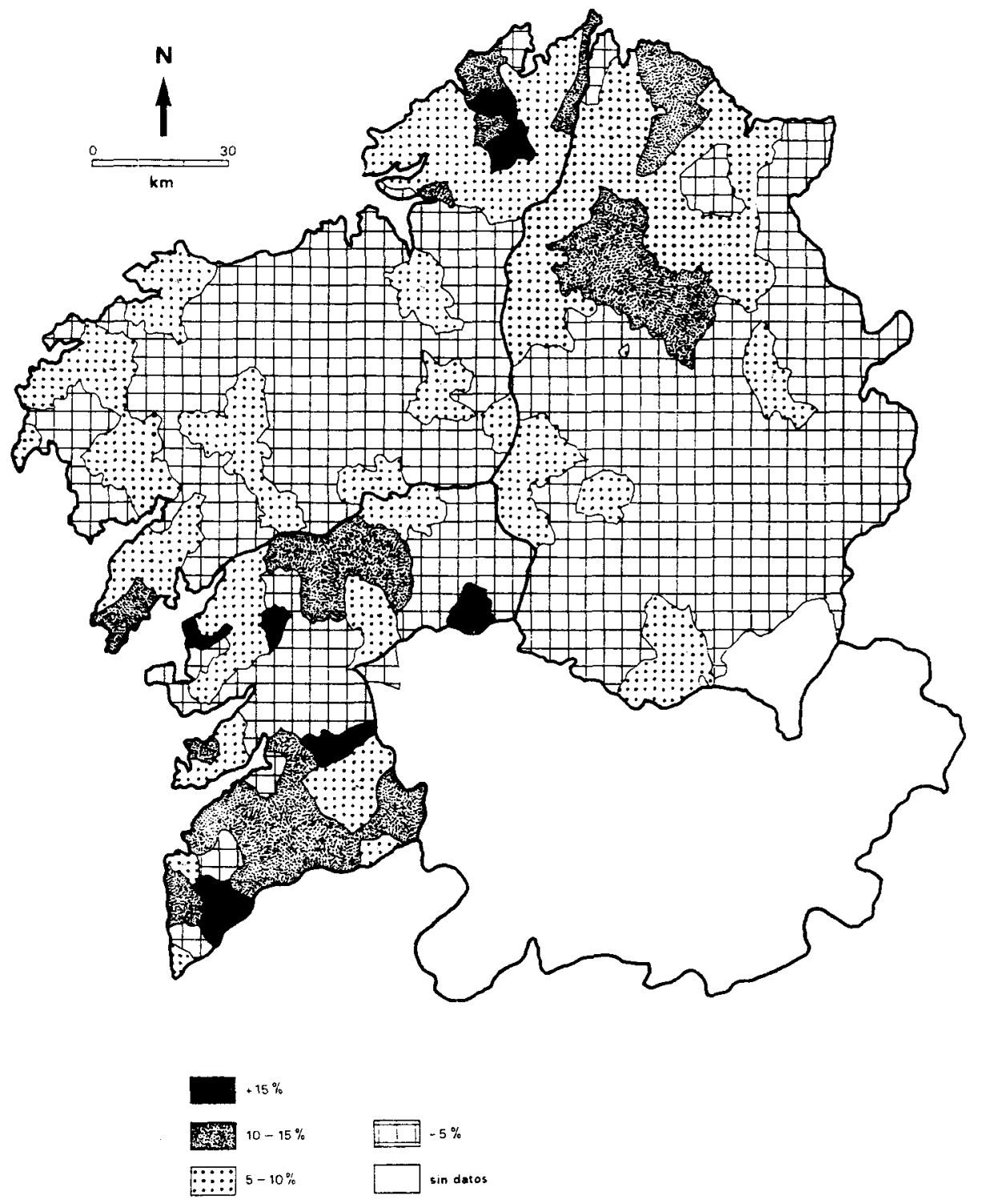

Mapa 4. Exceptuados por tener "casa abierta". 


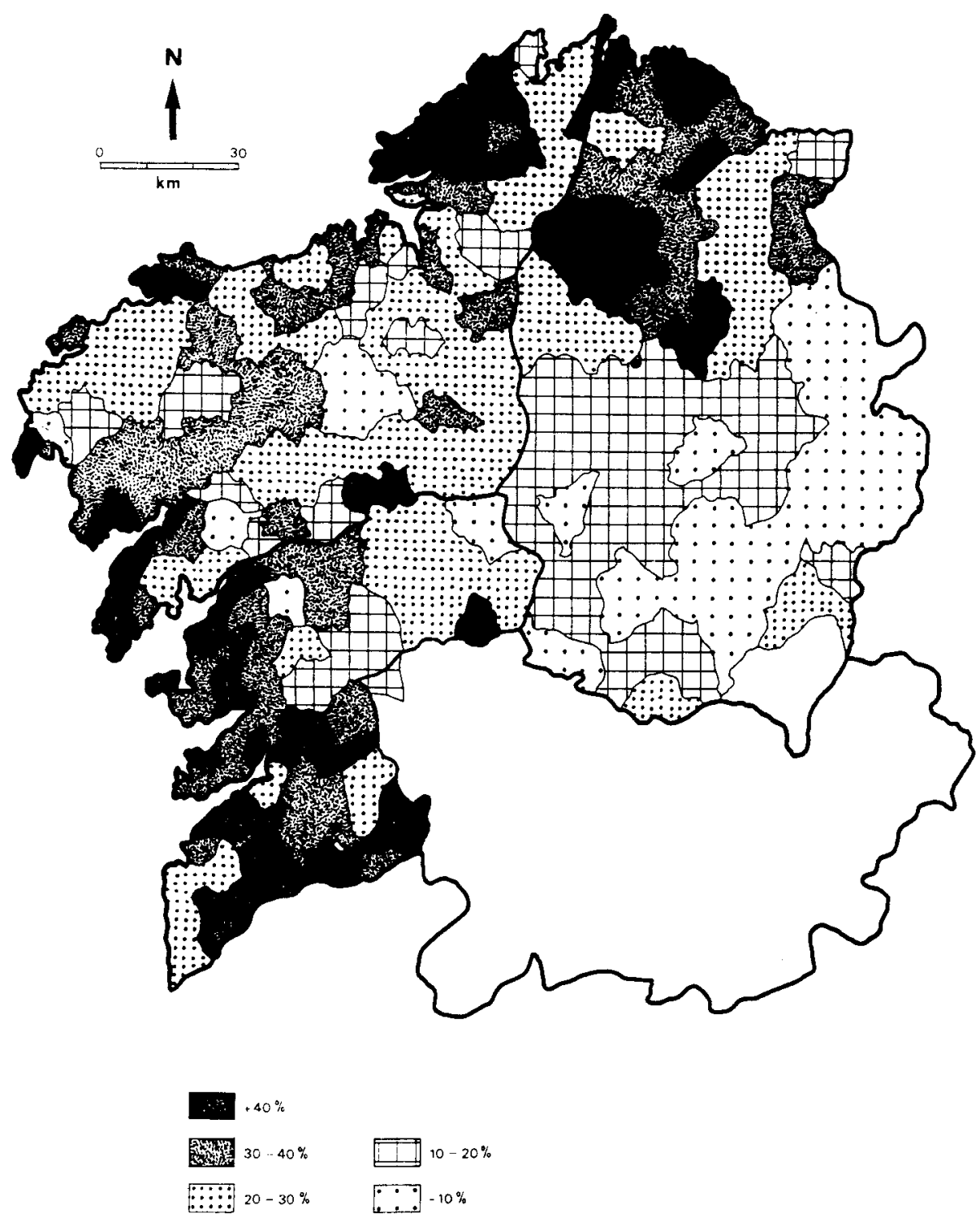

Mapa 5. Total excepciones por causa familiar. 


\section{LA EXENCIÓN POR INUTILIDAD FISICA}

Como se ha dicho ya, el número de impedidos para el servicio es muy inferior en el grupo de 16 a 18 años - $7,7 \%$, excluyendo Orense-que en el siguiente, pero en general la distribución de esta variante es bastante homogénea y rara vez hay más de un «inútil» por cada 10 alistados. Cabe señalar, no obstante, que en Galicia en el siglo xvIII, como después de 1837, hubo inutilizaciones voluntarias para eludir el servicio, lo que da una idea de la aversión a su cumplimiento ${ }^{22}$. La fuente que manejamos no permite saber en ningún momento si en el censo se incluyen o no los exentos de servicio por no alcanzar la talla reglamentaria; en caso de que no se hubieran incluido, podría explicarse por esta vía la diferencia numérica entre los censados en 1762 y los computados en el censo de 1787.

\section{EL FACTOR MIGRATORIO}

El censo de mozos de 1762 prevé una columna de «ausentes» que, salvo en el caso orensano, ofrece una perspectiva de valor inestimable para observar el efecto geográficamente diferenciado de la emigración - véase mapa 6-. Sus cifras guardan una notable coherencia, si bien es cierto que las ausencias debieron de estar limitadas por las excepciones como las reseñadas que permitian eludir el servicio de modo menos traumático; asimismo, es fácil comprobar que las localidades del litoral presentan un porcentaje de ausentes muy bajo por el efecto de la Matrícula de Mar.

Los resultados globales revelan que un $9,4 \%$ de los mozos de 16 a 18 años y un $18,7 \%$ en el tramo de 18 a 40 estaban ausentes en el momento de la ejecución del censo, sin duda un buen número para eludir el servicio, afectando de un modo especial a la mitad meridional de Galicia. Aunque es evidente que no todas las áreas de emigración están reflejadas en el mapa, también lo es que quedan bien señaladas aquellas otras que se caracterizan por su movilidad, lo que parece deberse a que los datos de la leva son menos sensibles a las migraciones estacionales que a las otras. En un $7,7 \%$ de los municipios el número de ausentes supera el $50 \%$ del total de mozos y un $10,8 \%$ tiene entre el 30 y el $50 \%$, coincidiendo ambos grupos con una amplia banda territorial que recorre la Galicia atlántica desde los concejos de la Costa de la Muerte hasta la

\footnotetext{
22 Borreguero, C., op. cit., págs. 318 y ss.
} 
Hombres y ejército en Galicia: La Leva de 1762

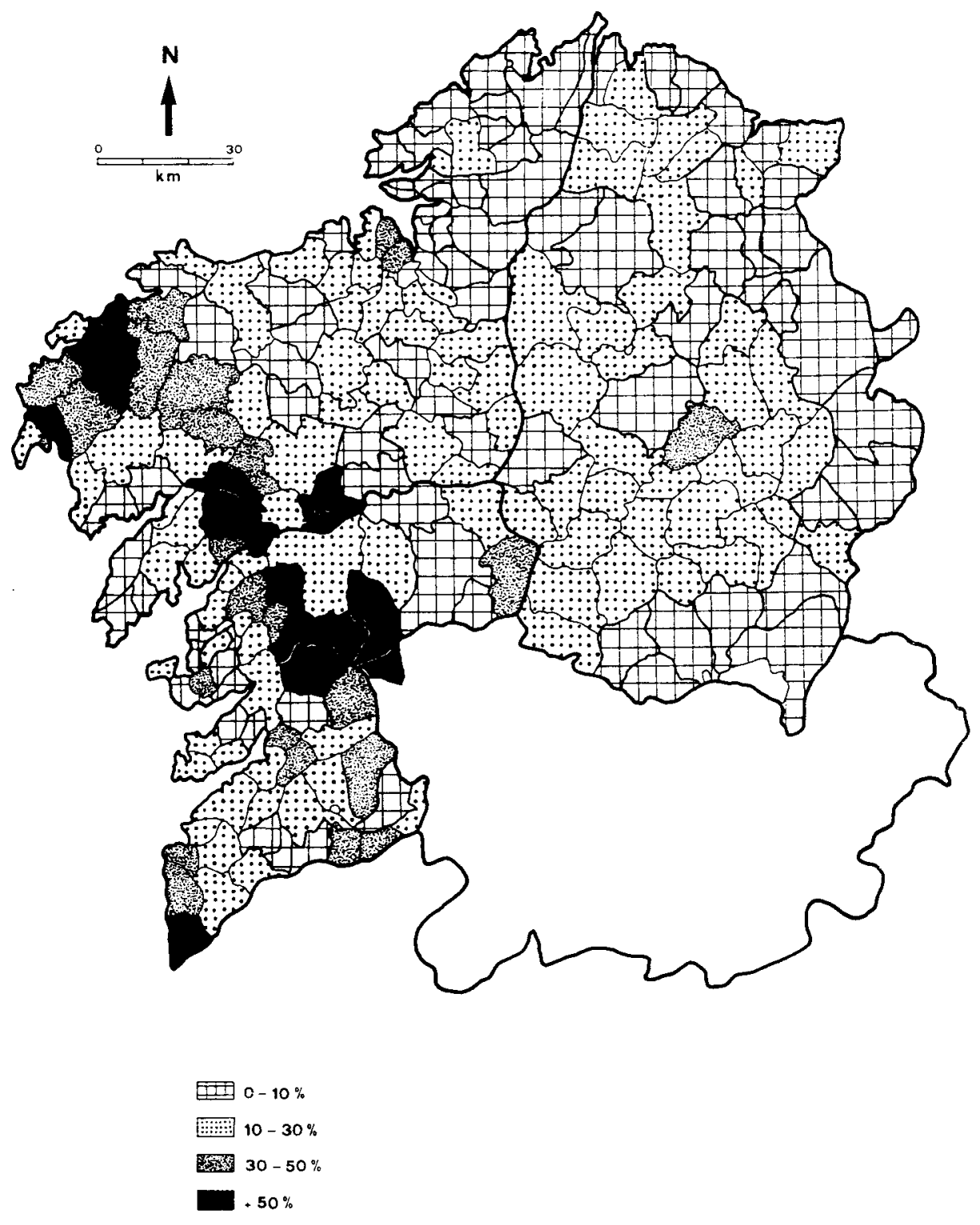

Mapa 6. Porcentaje de emigrantes. Leva de 1762. 
Cuenca del Ulla siguiendo una ruta que atraviesa los municipios de Zas, Sta. Comba, A Baña, Ames y Brión hasta llegar a los de Rois, Dodro, Padrón y Ponte Cesures, en la vertiente septentrional del Ulla; luego, en la actual provincia de Pontevedra, recorre los municipios interiores situados en la zona montañosa de la Dorsal gallega y alcanza la frontera de Portugal. Fuera de esa banda, se registra un fuerte número de ausentes en el entorno de la ciudad de La Coruña, en el extremo S.O. de Galicia y en la zona central de la provincia de.Lugo. Por el contrario, la práctica totalidad de esta última provincia aparece como de emigración escasa o nula, lo que sin duda se debe al predominio en esta zona de los movimientos de tipo estacional a Castilla.

Un dato de interés es el de las ausencias de menores de 18 años, que si bien no alcanzan el millar en toda Galicia, son más frecuentes allí donde lo es la emigración motivada por profesiones especializadas: en la comarca sudoccidental de A Guarda, tierra de canteros y mamposteros, estaban ausentes el $52,6 \%$ de los varones de $16 / 18$ años, lo mismo que sucedía, por razones similares, en las jurisdicciones pontevedresas de Montes y de Baños $-54,6 \%$ y $39,4 \%$ de ausentes respectivamente que conduce a pensar que habían salido de sus comunidades e incluso de Galicia como aprendices de esos oficios.

Si vinculamos todos los tipos de excepción, no hay duda de que las ausencias son más numerosas en las zonas donde las posibilidades de excepción eran menores, pero tampoco puede dudarse de que las ausencias sólo de modo parcial se justifican por razones militares, sino que coinciden con áreas densamente pobladas y con familias de pequeño tamaño que propiciaban una emigración temporal o definitiva con destino en Andalucia y en Portugal. Dicho de otro modo, el servicio militar fue un elemento coadyuvante pero no determinante de la emigración.

\section{Los no exceptuados}

Evidentemente, las excepciones más o menos demostradas reducen el contingente de varones útiles para el servicio de un modo drástico, pero las posibilidades de excepción, como hemos visto, vienen dadas por la estructura social -mayor o menor presencia de aforados de una u otra clase- y por los comportamientos y prácticas familiares, y en menor medida por la inutilidad física y sólo se introdujo como elemento distorsionador la ausencia de los implicados. No se puede pensar que todos los ausentes eran útiles para el servicio -quizá sí que lo eran en su mayoría-, pero la fuente que empleamos los considera como tales; por lo 
tanto, si se suman las columnas de útiles y de ausentes, el resultado global se modifica de forma sustancial:

\begin{tabular}{lccccr}
\hline \multicolumn{5}{c}{ Útiles + Ausentes } \\
\hline & \multicolumn{6}{c}{$16 / 18$ años } & \multicolumn{1}{c}{$18 / 40$ años } & $\%$ Ausen. \\
\hline Coruña & N. & $\%$ & N. & $\%$ & \\
Betanzos & 246 & 87,5 & 864 & 63,6 & 8,7 \\
Lugo & 721 & 81,7 & 2.537 & 58,5 & 8,0 \\
Santiago & 871 & 67,9 & 5.594 & 59,6 & 11,3 \\
Tuy & 2.797 & 79,3 & 8.499 & 59,4 & 24,8 \\
Mondoñedo & 1.069 & 76,7 & 2.832 & 51,2 & 19,7 \\
& 440 & 82,4 & 1.419 & 46,4 & 5,4 \\
\hline
\end{tabular}

Como puede verse, la utilidad plena para el servicio oscila en una banda no excesivamente ancha, en torno al $60 \%$ entre los mayores y cerca del $80 \%$ entre los más jóvenes, y las ausencias fueron un serio correctivo. Desde luego, la proporción de no exceptuados es en Orense, por las razones ya dichas, anómalamente baja, sólo el $20,8 \%$ en $18 / 40$ años y $4,6 \%$ en $16 / 18$, por lo que reiteramos la idea de una colaboración clara de quienes elaboraron las listas. No obstante, incluso en Orense se perciben variaciones zonales; el mapa 7 refleja la proporción de no exceptuados en los distintos municipios gallegos: la distribución marca una división clara a un lado y a otro de una diagonal al Sur de la cual queda Orense, cuya baja tasa de "útiles para el servicio" ya se ha justificado, la antigua provincia de Tuy, a causa de la elevada proporción de ausentes, y toda la provincia de Santiago, salvo sus comarcas más interiores, por idéntica razón; al Norte se sitúa toda la antigua provincia de Lugo y las de Betanzos, Mondoñedo y Coruña y la parte interior de Santiago, concentrándose los procentajes más elevados de útiles en la banda Norte del Sil y en la banda meridional del Miño.

En definitiva, quedaron sometidos al sorteo de los 1.154 hombres exigidos por la Corona un total de 13.288 varones, $58,1 \%$ mayores de 18 años y $41,9 \%$ menores de esa edad, cuando de partida se había contabilizado a 53.094 de $18 / 40$ años, el $82,4 \%$ y a 11.334 de $16 / 18$, el $17,6 \%$, de modo que la proporción se ha invertido después de la exclusión de las excepciones y ausencias. Las posibilidades estadísticas de entrar en el servicio militar se incrementaron de forma brutal: si en origen habrían implicado al $1,8 \%$ de los mozos censados, en el resultado final el porcentaje se eleva a $8,7 \%$, lo que es lo mismo, uno de cada 56 varones en el primer caso y uno de cada 11 en el segundo. 


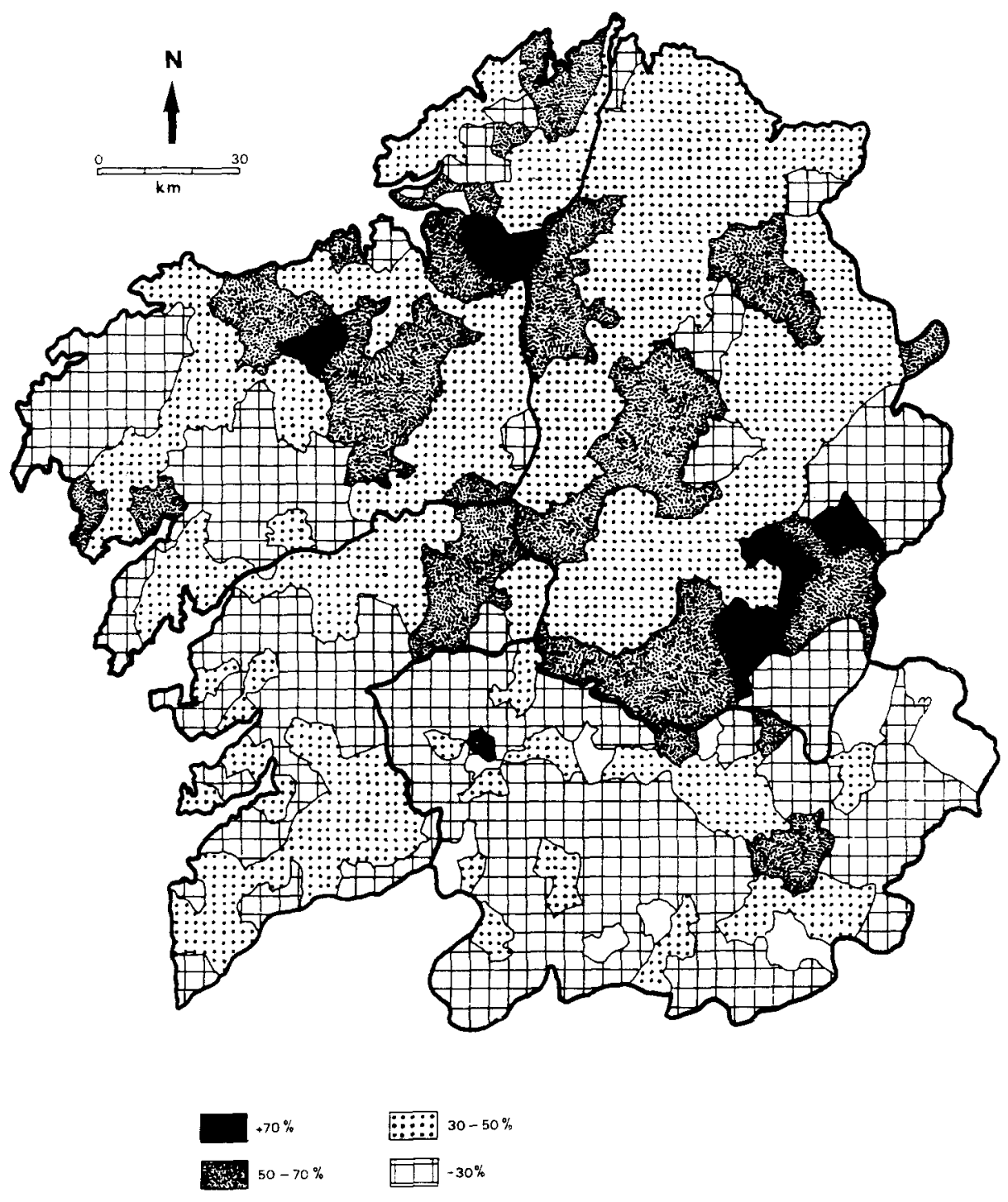

Mapa 7. «Sin excepción». 
APÉNDICE: Datos del Censo de Mozos de 1762. Varones de 18 a 40 años

* El listado que se ofrece sigue, dentro de cada provincia, un orden geográfico de Norte a Sur y de Oeste a Este.

PROVINCIA DE LA CORUÑA

\begin{tabular}{|c|c|c|c|c|c|c|c|}
\hline Municipio & Nobles & $\begin{array}{l}\text { Hijos } \\
\text { únicos }\end{array}$ & $\begin{array}{c}\text { Cabeza } \\
\text { casa }\end{array}$ & $\begin{array}{c}\text { Sin } \\
\text { excep. }\end{array}$ & Austs. & Inútiles & Total \\
\hline & $\%$ & $\%$ & $\%$ & $\%$ & $\%$ & $\%$ & Casos \\
\hline Valdoviño & 3,0 & 45,5 & 7,6 & 42,4 & 1,5 & 0,0 & 67 \\
\hline Cedeira & 7,5 & 34,0 & 11,3 & 47,2 & 0,0 & 0,0 & 53 \\
\hline Cariño & 0,0 & 16,3 & 0,0 & 63,6 & 0,0 & 20,0 & 55 \\
\hline Cerdido & 0,0 & 55,5 & 18,5 & 7,4 & 0,0 & 18,5 & 27 \\
\hline Ortigueira & 1,4 & 23,3 & 5,4 & 55,0 & 0,0 & 14,6 & 725 \\
\hline Mañón & 1,5 & 34,5 & 12,4 & 45,9 & 0,5 & 5,2 & 194 \\
\hline Ferrol & 0,9 & 48,0 & 7,7 & 33,6 & 0,0 & 9,6 & 104 \\
\hline Narón & 1,7 & 42,0 & 7,5 & 30,5 & 6,9 & 11,5 & 174 \\
\hline Neda & 5,6 & 39,4 & 7,0 & 18,3 & 18,3 & 5,6 & 71 \\
\hline Fene & 0,0 & 28,4 & 5,4 & 60,8 & 0,0 & 6,8 & 74 \\
\hline Mugardos & 0,0 & 22,9 & 8,6 & 48,6 & 0,0 & 17,1 & 35 \\
\hline Ares & 4,9 & 18,0 & 4,9 & 68,9 & 0,0 & 3,3 & 61 \\
\hline Cabanas & 0,0 & 23,9 & 12,7 & 35,2 & 2,8 & 25,4 & 71 \\
\hline Capela & 0,0 & 26,5 & 6,1 & 55,1 & 2,0 & 10,2 & 49 \\
\hline S. Sadurniño & 0,0 & 46,0 & 9,9 & 24,1 & 10,6 & 9,2 & 141 \\
\hline Moeche & 2,4 & 22,9 & 13,2 & 55,4 & 0,0 & 6,0 & 83 \\
\hline Somozas & 0,0 & 25,3 & 17,6 & 42,9 & 8,8 & 5,5 & 91 \\
\hline As Pontes & 0,0 & 21,0 & 4,6 & 46,7 & 7,2 & 20,0 & 195 \\
\hline A Coruña & 7,2 & 14,1 & 0,8 & 68,9 & 1,2 & 1,2 & 248 \\
\hline Oleiros & 10,1 & 26,8 & 3,6 & 29,7 & 24,6 & 3,6 & 138 \\
\hline Sada & 9,0 & 20,7 & 1,8 & 27,9 & 35,2 & 5,4 & 111 \\
\hline Bergondo & 0,0 & 15,1 & 3,1 & 36,5 & 34,0 & 10,7 & 159 \\
\hline Miño & 7,0 & 27,9 & 4,7 & 53,5 & 0,0 & 10,5 & 86 \\
\hline Pontedeume & 2,3 & 22,3 & 3,1 & 50,0 & 3,0 & 14,6 & 130 \\
\hline Vilamaior & 1,3 & 21,3 & 4,0 & 66,7 & 2,7 & 4,0 & 75 \\
\hline Monfero & 0,0 & 15,4 & 1,3 & 77,8 & 0,7 & 4,7 & 149 \\
\hline Malpica & 1,7 & 25,9 & 6,9 & 39,7 & 13,8 & 12,0 & 58 \\
\hline Ponteceso & 3,3 & 37,0 & 7,9 & 33,7 & 9,0 & 10,1 & 89 \\
\hline Laxe & 0,0 & 22,7 & 2,3 & 6,8 & 59,0 & 9,0 & 44 \\
\hline Cabana & 0,0 & 22,7 & 1,7 & 16,3 & 47,7 & 11,6 & 172 \\
\hline Coristanco & 4,0 & 32,7 & 2,0 & 42,0 & 6,7 & 13,3 & 150 \\
\hline Carballo & 3,0 & 26,1 & 1,0 & 50,3 & 11,0 & 8,5 & 199 \\
\hline Laracha & 2,4 & 26,9 & 3,6 & 55,7 & 4,8 & 6,0 & 167 \\
\hline Arteixo & 0,7 & 21,3 & 0,0 & 42,0 & 15,3 & 20,7 & 150 \\
\hline Culleredo & 1,9 & 32,1 & 0,9 & 43,4 & 13,2 & 8,5 & 106 \\
\hline Cerceda & 0,0 & 22,3 & 4,6 & 69,2 & 3,8 & 0,0 & 130 \\
\hline Carral & 2,9 & 13,9 & 1,5 & 56,2 & 21,2 & 4,4 & 137 \\
\hline Cambre & 7,4 & 13,5 & 4,0 & 48,0 & 18,2 & 8,8 & 148 \\
\hline
\end{tabular}


(Continuación):

PROVINCIA DE LA CORUÑA

\begin{tabular}{|c|c|c|c|c|c|c|c|}
\hline Municipio & Nobles & $\begin{array}{c}\text { Hijos } \\
\text { únicos }\end{array}$ & $\begin{array}{c}\text { Cabeza } \\
\text { casa }\end{array}$ & $\begin{array}{c}\text { Sin } \\
\text { excep. }\end{array}$ & Austs. & Inútiles & Total \\
\hline & $\%$ & $\%$ & $\%$ & $\%$ & $\%$ & $\%$ & Casos \\
\hline Abegondo & 4,2 & 18,8 & 3,4 & 47,1 & 20,7 & 5,0 & 261 \\
\hline Betanzos & 3,2 & 17,8 & 5,4 & 48,1 & 8,6 & 9,2 & 185 \\
\hline Paderne & 0,9 & 27,0 & 7,0 & 51,3 & 9,6 & 4,3 & 115 \\
\hline Coirós & 2,5 & 15,0 & 8,8 & 45,0 & 17,5 & 11,2 & 80 \\
\hline Oza dos Ríos & 0,0 & 14,6 & 5,9 & 58,3 & 11,0 & 10,2 & 25 \\
\hline Cesuras & 7,8 & 12,7 & 2,0 & 58,0 & 15,6 & 4,4 & 205 \\
\hline Irixoa & 1,1 & 21,1 & 3,3 & 67,8 & 6,7 & 0,0 & 90 \\
\hline Aranga & 7,1 & 35,7 & 1,8 & 36,6 & 8,9 & 9,8 & 112 \\
\hline Curtis & 6,2 & 25,7 & 3,1 & 27,8 & 23,7 & 13,4 & 97 \\
\hline Camariñas & 6,5 & 35,5 & 3,2 & 0,0 & 22,6 & 25,8 & 31 \\
\hline Muxía & 3,7 & 20,1 & 6,9 & 15,3 & 41,3 & 12,7 & 189 \\
\hline Vimianzo & 0,5 & 19,9 & 5,0 & 2,0 & 59,2 & 13,4 & 201 \\
\hline Zas & 2,5 & 18,2 & 1,9 & 16,7 & 47,2 & 12,6 & 159 \\
\hline Sta. Comba & 0,3 & 17,9 & 1,6 & 36,5 & 31,7 & 11,5 & 312 \\
\hline Tordoia & 0,0 & 29,5 & 3,3 & 45,1 & 9,8 & 12,3 & 122 \\
\hline Val do Dubra & 1,5 & 21,6 & 8,2 & 28,3 & 23,1 & 17,2 & 134 \\
\hline Trazo & 1,7 & 32,5 & 4,3 & 43,6 & 0,9 & 17,1 & 117 \\
\hline Ordes & 4,7 & 3,5 & 2,9 & 59,6 & 12,9 & 14,0 & 171 \\
\hline Oroso & 2,7 & 3,6 & 1,8 & 54,0 & 22,5 & 12,6 & 111 \\
\hline Frades & 9,9 & 6,6 & 3,3 & 56,0 & 13,2 & 8,8 & 91 \\
\hline Mesía & 1,0 & 16,1 & 4,0 & 51,5 & 9,0 & 18,2 & 99 \\
\hline Vilasantar & 2,4 & 14,6 & 8,5 & 35,4 & 20,7 & 14,6 & 82 \\
\hline Boimorto & 9,4 & 27,0 & 5,2 & 39,6 & 7,3 & 10,4 & 96 \\
\hline Sobrado & 7,1 & 25,7 & 2,9 & 45,7 & 11,4 & 7,1 & 70 \\
\hline Toques & 2,1 & 15,0 & 5,4 & 28,0 & 22,6 & 22,6 & 93 \\
\hline Fisterra & 2,4 & 31,7 & 9,8 & 26,8 & 14,6 & 12,2 & 41 \\
\hline Corcubión & 0,0 & 35,3 & 0,0 & 0,0 & 47,0 & 17,6 & 17 \\
\hline Cee & 1,3 & 6,8 & 0,0 & 12,3 & 76,7 & 2,7 & 73 \\
\hline Dumbría & 1,9 & 12,3 & 3,8 & 30,2 & 45,3 & 6,6 & 106 \\
\hline Mazaricos & 0,0 & 32,0 & 5,0 & 37,1 & 12,4 & 13,5 & 178 \\
\hline Negreira & 0,3 & 38,1 & 1,4 & 23,5 & 19,0 & 7,6 & 289 \\
\hline A Baña & 0,0 & 22,2 & 8,9 & 29,6 & 31,9 & 7,4 & 135 \\
\hline Ames & 0,0 & 22,3 & 5,0 & 16,6 & 47,8 & 8,3 & 301 \\
\hline Santiago & 3,2 & 18,1 & 3,6 & 56,3 & 11,3 & 6,0 & 662 \\
\hline O Pino & 2,3 & 16,9 & 4,7 & 58,2 & 9,4 & 8,5 & 213 \\
\hline Touro & 0,4 & 32,0 & 8,2 & 46,5 & 5,5 & 7,4 & 256 \\
\hline Arzúa & 1,8 & 25,4 & 2,2 & 46,9 & 9,8 & 12,9 & 224 \\
\hline Santiso & 1,4 & 18,3 & 1,4 & 57,7 & 10,6 & 10,6 & 142 \\
\hline Melide & 5,5 & 27,6 & 1,2 & 35,6 & 7,4 & 20,9 & 163 \\
\hline Carnota & 0,0 & 34,4 & 1,1 & 42,2 & 15,7 & 7,8 & 90 \\
\hline Muros & 0,7 & 35,8 & 4,4 & 46,0 & 2,2 & 9,5 & 137 \\
\hline Outes & 0,0 & 26,0 & 5,9 & 50,0 & 2,9 & 15,2 & 204 \\
\hline Noia & 7,7 & 37,6 & 4,3 & 19,7 & 24,8 & 6,0 & 117 \\
\hline Lousame & 0,0 & 27,1 & 5,9 & 35,6 & 12,7 & 16,9 & 118 \\
\hline
\end{tabular}


(Continuación):

PROVINCIA DE LA CORUÑA

\begin{tabular}{lccrrrrr}
\hline Municipio & Nobles & $\begin{array}{c}\text { Hijos } \\
\text { únicos }\end{array}$ & $\begin{array}{c}\text { Cabeza } \\
\text { casa }\end{array}$ & $\begin{array}{c}\text { Sin } \\
\text { excep. }\end{array}$ & Austs. & Inútiles & Total \\
\hline & $\%$ & $\%$ & $\%$ & $\%$ & $\%$ & $\%$ & Casos \\
Brión & 1,3 & 9,7 & 2,6 & 10,6 & 73,1 & 2,6 & 227 \\
Rois & 0,4 & 0,7 & 0,4 & 0,7 & 92,9 & 4,9 & 283 \\
Padrón & 2,4 & 8,0 & 3,8 & 17,9 & 58,0 & 7,5 & 212 \\
Teo & 0,0 & 9,1 & 2,7 & 9,4 & 69,4 & 6,0 & 297 \\
Vedra & 1,5 & 10,7 & 3,7 & 19,9 & 57,6 & 6,6 & 271 \\
Boqueixón & 0,0 & 24,1 & 9,2 & 42,0 & 16,1 & 8,6 & 174 \\
Porto do Son & 2,0 & 31,5 & 9,6 & 24,0 & 6,2 & 26,7 & 146 \\
Ribeira & 0,0 & 36,1 & 10,2 & 25,0 & 3,7 & 25,0 & 108 \\
Pob. Caramiñal & 51, & 26,3 & 11,0 & 32,2 & 5,9 & 19,5 & 118 \\
Boiro & 0,4 & 16,7 & 5,6 & 48,0 & 22,2 & 7,1 & 252 \\
Rianxo & 0,8 & 24,6 & 4,8 & 47,2 & 18,3 & 4,8 & 252 \\
Dodro & 0,0 & 22,4 & 4,5 & 32,7 & 35,3 & 3,8 & 156
\end{tabular}

PROVINCIA DE LUGO

$\begin{array}{lrrrrrrr}\text { O Vicedo } & 4,2 & 80,0 & 0,0 & 8,6 & 0,0 & 7,1 & 70 \\ \text { Viveiro } & 3,2 & 28,4 & 6,3 & 31,2 & 10,4 & 20,5 & 319 \\ \text { Xove } & 3,3 & 28,3 & 13,9 & 35,0 & 5,0 & 14,4 & 180 \\ \text { Cervo } & 2,6 & 33,3 & 12,3 & 37,7 & 0,0 & 14,0 & 114 \\ \text { Foz } & 8,0 & 26,3 & 7,3 & 37,2 & 6,9 & 14,2 & 274 \\ \text { Ourol } & 0,0 & 22,2 & 6,3 & 46,2 & 10,8 & 14,6 & 158 \\ \text { Muras } & 1,9 & 25,5 & 7,8 & 46,0 & 8,8 & 9,8 & 102 \\ \text { Valadouro } & 3,1 & 22,4 & 10,2 & 33,7 & 15,3 & 15,3 & 98 \\ \text { Alfoz } & 2,0 & 42,9 & 8,2 & 28,0 & 12,2 & 6,1 & 196 \\ \text { Mondoñedo } & 7,4 & 23,5 & 1,2 & 45,7 & 9,9 & 12,3 & 162 \\ \text { Lourenzá } & 16,0 & 22,4 & 5,7 & 39,7 & 12,6 & 3,4 & 174 \\ \text { Barreiros } & 8,9 & 20,4 & 6,3 & 48,7 & 7,3 & 8,4 & 191 \\ \text { Ribadeo } & 24,8 & 8,3 & 4,8 & 32,4 & 29,0 & 0,0 & 145 \\ \text { Trabada } & 31,5 & 27,4 & 4,0 & 27,4 & 7,3 & 2,4 & 124 \\ \text { Xermade } & 0,0 & 33,3 & 6,2 & 55,0 & 3,0 & 8,7 & 80 \\ \text { Vilalba } & 4,5 & 29,1 & 11,4 & 35,3 & 6,2 & 13,0 & 422 \\ \text { Abadín } & 5,0 & 28,7 & 8,4 & 33,1 & 11,9 & 10,9 & 202 \\ \text { Pastoriza } & 0,1 & 18,6 & 9,3 & 50,4 & 8,6 & 11,4 & 280 \\ \text { Riotorto } & 2,6 & 20,5 & 7,7 & 64,1 & 0,0 & 5,1 & 78 \\ \text { Pontenova } & 8,8 & 34,6 & 2,5 & 42,1 & 4,4 & 7,5 & 159 \\ \text { Guitiriz } & 4,5 & 14,9 & 5,0 & 50,7 & 15,9 & 9,0 & 201 \\ \text { Begonte } & 3,2 & 17,5 & 3,7 & 43,8 & 18,4 & 13,4 & 217 \\ \text { Cospeito } & 7,3 & 27,4 & 10,6 & 31,8 & 15,1 & 7,8 & 179 \\ \text { Rábade } & 0,0 & 25,0 & 8,3 & 66,7 & 0,0 & 0,0 & 12 \\ \text { Outeiro Rey } & 8,0 & 9,5 & 4,5 & 55,7 & 15,9 & 4,9 & 264 \\ \text { Castro Rey } & 5,2 & 34,6 & 11,1 & 23,5 & 8,5 & 17,0 & 153 \\ \text { Pol } & 4,8 & 24,2 & 2,4 & 31,5 & 17,6 & 17,0 & 165 \\ \text { Meira } & 1,7 & 13,4 & 9,2 & 62,2 & 5,9 & 7,6 & 119 \\ \text { Ribeira Piquín } & 19,7 & 4,5 & 1,5 & 54,5 & 9,1 & 10,6 & 66\end{array}$


(Continuación):

PROVINCIA DE LUGO

\begin{tabular}{lrrrrrrr}
\hline Municipio & Nobles & $\begin{array}{r}\text { Hijos } \\
\text { únicos }\end{array}$ & $\begin{array}{c}\text { Cabeza } \\
\text { casa }\end{array}$ & $\begin{array}{c}\text { Sin } \\
\text { excep. }\end{array}$ & Austs. & Inútiles & Total \\
\hline & $\%$ & $\%$ & $\%$ & $\%$ & $\%$ & $\%$ & Casos \\
A Fonsagrada & 48,5 & 6,5 & 1,2 & 32,5 & 5,9 & 11,8 & 169 \\
Negueira Muñ. & 50,0 & 0,0 & 0,0 & 50,0 & 0,0 & 0,0 & 6 \\
Friol & 3,2 & 10,8 & 4,4 & 34,2 & 25,9 & 20,9 & 158 \\
Lugo & 3,4 & 10,0 & 0,3 & 68,3 & 8,6 & 9,4 & 350 \\
Corgo & 14,5 & 8,0 & 1,6 & 21,0 & 41,1 & 11,3 & 124 \\
Castroverde & 7,7 & 7,3 & 2,8 & 43,5 & 21,8 & 16,5 & 248 \\
Baleira & 26,5 & 5,0 & 6,1 & 33,7 & 18,8 & 9,9 & 181 \\
Navia Suarna & 83,8 & 1,2 & 0,6 & 11,3 & 0,6 & 2,5 & 160 \\
Palas & 6,3 & 8,9 & 6,8 & 43,2 & 8,4 & 24,7 & 190 \\
Monterroso & 2,5 & 4,5 & 4,1 & 54,5 & 10,7 & 23,1 & 121 \\
Guntín & 5,8 & 15,3 & 0,5 & 55,8 & 15,3 & 7,4 & 190 \\
Portomarín & 1,3 & 3,8 & 7,7 & 43,6 & 20,5 & 19,2 & 78 \\
Páramo & 7,2 & 11,2 & 2,4 & 58,4 & 16,0 & 4,8 & 125 \\
Láncara & 14,1 & 9,8 & 2,4 & 38,0 & 27,3 & 7,8 & 205 \\
Baralla & 13,1 & 8,6 & 1,5 & 36,9 & 22,7 & 17,2 & 198 \\
Becerreá & 45,0 & 6,3 & 1,3 & 25,8 & 12,5 & 8,8 & 240 \\
Triacastela & 6,0 & 8,4 & 1,2 & 51,8 & 15,7 & 16,9 & 83 \\
As Nogais & 20,6 & 3,1 & 0,0 & 75,0 & 0,0 & 1,2 & 160 \\
Cervantes & 63,2 & 2,1 & 0,0 & 25,5 & 4,7 & 4,7 & 337 \\
Antas de Ulla & 3,0 & 8,0 & 7,4 & 61,7 & 12,3 & 7,4 & 162 \\
Toboada & 9,2 & 11,6 & 2,8 & 48,9 & 11,2 & 16,0 & 249 \\
Paradela & 2,7 & 12,2 & 2,7 & 45,3 & 19,6 & 17,6 & 148 \\
Sarria & 9,7 & 4,6 & 1,3 & 46,4 & 26,2 & 11,8 & 237 \\
O Incio & 9,7 & 5,1 & 0,0 & 49,4 & 17,3 & 5,5 & 237 \\
Samos & 2,0 & 0,0 & 0,0 & 70,0 & 20,0 & 8,0 & 50 \\
Pedrafita & 5,9 & 10,2 & 2,5 & 56,0 & 15,3 & 10,2 & 118 \\
Chantada & 16,4 & 13,0 & 1,3 & 37,0 & 15,1 & 17,2 & 238 \\
Saviñao & 20,7 & 8,7 & 2,0 & 40,2 & 16,3 & 12,0 & 343 \\
Bóveda & 19,5 & 0,7 & 2,7 & 63,1 & 14,8 & 0,7 & 149 \\
Podra Brollón & 6,7 & 3,8 & 2,6 & 80,6 & 3,7 & 2,6 & 268 \\
Folgoso Caurel & 3,0 & 28,0 & 0,0 & 61,0 & 2,0 & 6,0 & 100 \\
Carballedo & 1,9 & 8,7 & 0,0 & 54,8 & 12,5 & 22,1 & 104 \\
Pantón & 14,4 & 12,8 & 4,0 & 55,2 & 5,3 & 8,5 & 375 \\
Sober & 5,5 & 20,0 & 5,5 & 58,2 & 3,6 & 6,4 & 220 \\
Monforte & 10,0 & 10,3 & 6,1 & 60,5 & 5,8 & 4,9 & 329 \\
& & & & & & &
\end{tabular}

\section{PROVINCIA DE PONTEVEDRA}

$\begin{array}{lrrrrrrr}\text { Vila de Cruces } & 1,2 & 18,6 & 9,6 & 47,0 & 3,0 & 8,4 & 429 \\ \text { Golada } & 3,8 & 6,3 & 1,6 & 52,4 & 18,9 & 17,0 & 317 \\ \text { Ponte Cesures } & 0,0 & 25,8 & 6,5 & 12,9 & 51,6 & 3,2 & 31 \\ \text { Valga } & 0,8 & 35,4 & 5,5 & 34,6 & 18,9 & 4,7 & 127 \\ \text { Catoira } & 0,0 & 48,6 & 5,6 & 25,0 & 18,0 & 2,8 & 72 \\ \text { Vila García } & 2,9 & 32,4 & 8,7 & 24,3 & 14,4 & 16,8 & 173\end{array}$


(Continuación):

PROVINCIA DE PONTEVEDRA

\begin{tabular}{|c|c|c|c|c|c|c|c|}
\hline Municipio & Nobles & $\begin{array}{c}\text { Hijos } \\
\text { únicos }\end{array}$ & $\begin{array}{c}\text { Cabeza } \\
\text { casa }\end{array}$ & $\underset{\text { excep. }}{\operatorname{Sin}}$ & Austs. & Inútiles & Total \\
\hline & $\%$ & $\%$ & $\%$ & $\%$ & $\%$ & $\%$ & Casos \\
\hline Cuntis & 0,7 & 9,3 & 0,4 & 16,8 & 64,5 & 8,2 & 279 \\
\hline Caldas Reis & 1,0 & 27,6 & 6,8 & 23,4 & 34,4 & 6,8 & 192 \\
\hline Moraña & 0,0 & 24,0 & 15,3 & 11,3 & 47,3 & 2,0 & 150 \\
\hline A Estrada & 1,1 & 20,8 & 11,3 & 45,1 & 14,9 & 7,0 & 885 \\
\hline Silleda & 2,0 & 16,4 & 9,9 & 48,7 & 11,5 & 10,7 & 384 \\
\hline Lalín & 0,0 & 19,3 & 0,9 & 59,8 & 1,5 & 17,2 & 331 \\
\hline Forcarey & 0,3 & 9,6 & 7,3 & 9,4 & 64,0 & 9,4 & 342 \\
\hline Dozón & 3,0 & 32,3 & 26,1 & 23.0 & 0,0 & 15,4 & 65 \\
\hline Rodeiro & 1,3 & 21,3 & 0,0 & 37,3 & 30,7 & 9,3 & 75 \\
\hline O Grove & 4,0 & 48,0 & 0,0 & 4,0 & 20,0 & 20,0 & 25 \\
\hline Gambados & 8,0 & 26,1 & 3,4 & 30,7 & 7,0 & 25,0 & 88 \\
\hline Vila Nova A. & 10,5 & 35,5 & 15,8 & 14,5 & 6,6 & 17,1 & 76 \\
\hline Rivadumia & 0,0 & 33,3 & 2,0 & 33,3 & 10,0 & 21,6 & 51 \\
\hline Meaño & 0,0 & 26,2 & 5,8 & 20,4 & 32,0 & 14,6 & 103 \\
\hline Meis & 5,0 & 41,4 & 9,1 & 10,1 & 6,0 & 28,3 & 99 \\
\hline Portas & 4,8 & 46,8 & 9,7 & 12,9 & 17,7 & 8,1 & 62 \\
\hline Barro & 0,9 & 29,4 & 8,3 & 40,4 & 17,4 & 3,7 & 109 \\
\hline Campo Lameiro & 0,0 & 17,3 & 4,5 & 8,2 & 62,7 & 7,3 & 110 \\
\hline Cotobade & 0,0 & 14,8 & 1,2 & 14,0 & 52,0 & 18,0 & 256 \\
\hline Cerdedo & 0,0 & 6,0 & 3,9 & 2,6 & 68,8 & 18,6 & 231 \\
\hline Beariz & 0,0 & 6,4 & 4,0 & 4,0 & 64,0 & 21,6 & 125 \\
\hline Sanxenxo & 5,3 & 31,0 & 3,5 & 13,3 & 6,2 & 21,2 & 113 \\
\hline Poio & 0,0 & 47,4 & 0,0 & 42,1 & 0,0 & 15,8 & 19 \\
\hline Marín & 6,8 & 28,8 & 5,0 & 37,3 & 5,1 & 13,6 & 59 \\
\hline Vilaboa & 0,0 & 57,3 & 2,5 & 30,0 & 2,5 & 7,5 & 40 \\
\hline Pontevedra & 3,7 & 31,7 & 3,7 & 28,9 & 19,4 & 9,3 & 356 \\
\hline Soutomaior & 0,0 & 29,9 & 13,4 & 6,0 & 34,8 & 14,9 & 67 \\
\hline Ponte Caldelas & 0,9 & 45,7 & 3,8 & 32,4 & 7,6 & 9,5 & 195 \\
\hline A Lama & 0,0 & 27,9 & 3,3 & 27,9 & 32,1 & 8,8 & 215 \\
\hline Fornelos & 0,0 & 24,4 & 15,6 & 44,4 & 11,1 & 4,4 & 45 \\
\hline Bueu & 3,0 & 38,8 & 11,9 & 20,9 & 11,9 & 13,4 & 67 \\
\hline Cangas Morrazo & 6,9 & 29,7 & 5,0 & 37,6 & 4,0 & 14,9 & 101 \\
\hline Moaña & 2,4 & 29,8 & 8,3 & 28,6 & 18,0 & 13,1 & 84 \\
\hline Vigo & 5,8 & 34,3 & 13,1 & 19,5 & 8,7 & 18,0 & 344 \\
\hline Redondela & 2,4 & 24,8 & 4,4 & 33,5 & 26,7 & 6,8 & 206 \\
\hline Mos & 0,0 & 29,0 & 11,9 & 24,4 & 26,1 & 8,0 & 176 \\
\hline Pazos Borbén & 0,0 & 27,1 & 11,6 & 18,6 & 40,0 & 3,1 & 129 \\
\hline Ponteareas & 1,8 & 28,7 & 10,2 & 33,2 & 19,3 & 5,7 & 509 \\
\hline Mondariz B. & 0,0 & 32,0 & 9,0 & 37,2 & 21,8 & 1,3 & 78 \\
\hline Mondariz & 2,7 & 23,8 & 7,3 & 40,2 & 18,0 & 7,7 & 261 \\
\hline Covelo & 0,0 & 16,7 & 7,0 & 39,6 & 30,4 & 6,2 & 227 \\
\hline A Cañiza & 0,5 & 31,7 & 11,6 & 34,6 & 9,5 & 12,1 & 379 \\
\hline Nigrán & 1,5 & 19,8 & 10,8 & 44,2 & 13,1 & 10,8 & 344 \\
\hline Baiona & 3,1 & 15,6 & 5,5 & 20,3 & 45,3 & 8,6 & 128 \\
\hline
\end{tabular}


(Continuación):

PROVINCIA DE PONTEVEDRA

\begin{tabular}{lccrrrrr}
\hline Municipio & Nobles & $\begin{array}{c}\text { Hijos } \\
\text { únicos }\end{array}$ & $\begin{array}{c}\text { Cabeza } \\
\text { casa }\end{array}$ & $\begin{array}{c}\text { Sin } \\
\text { excep. }\end{array}$ & Austs. & Inútiles & Total \\
\hline Oia & $\%$ & $\%$ & $\%$ & $\%$ & $\%$ & $\%$ & Casos \\
Rosal & 0,0 & 12,2 & 10,8 & 39,2 & 37,8 & 0,0 & 74 \\
A Guarda & 0,0 & 23,3 & 0,9 & 10,3 & 58,6 & 6,9 & 116 \\
Tomiño & 2,9 & 17,6 & 7,4 & 10,3 & 51,5 & 10,3 & 68 \\
Gondomar & 1,8 & 26,1 & 15,3 & 35,1 & 17,1 & 2,7 & 111 \\
Porriño & 1,7 & 19,2 & 5,5 & 34,0 & 28,3 & 11,0 & 526 \\
Tuy & 1,2 & 38,0 & 11,0 & 38,7 & 7,4 & 3,1 & 163 \\
Salceda & 0,4 & 43,0 & 13,1 & 22,1 & 10,2 & 9,8 & 244 \\
Salvaterra & 4,8 & 41,3 & 9,6 & 28,8 & 3,8 & 10,6 & 104 \\
As Neves & 1,0 & 43,2 & 9,6 & 33,7 & 7,6 & 4,6 & 303 \\
Arbo & 0,8 & 29,6 & 10,8 & 22,3 & 33,8 & 2,7 & 260 \\
Crecente & 0,4 & 31,2 & 7,9 & 20,1 & 31,6 & 8,7 & 253 \\
- & 1,7 & 34,8 & 12,3 & 24,9 & 10,9 & 15,0 & 293 \\
\hline
\end{tabular}

No se ofrecen los listados de la provincia de Orense debido a las deficiencias señaladas en el texto. 